\title{
Publish or perish - but where?
}

\author{
Rossouw von Solms rossouw@nmmu.ac.za (CORRESPonding), \\ Basie von Solms basievs@uj.ac.za \\ a Nelson Mandela Metropolitan University, Port Elizabeth, South Africa \\ ${ }^{b}$ University of Johannesburg, Johannesburg, South Africa
}

\section{INTRODUCTION}

'Publish or perish' has been advocated amongst the academic fraternity for decades. As early as 1942, the term has been linked to academic and research contexts (Garfield, 1996). For the last decade, the term has regularly been associated with the pressures in academia to establish, maintain and enhance the career of an academic (Fanelli, 2010; Neill, 2008; Gad-el-Hak, 2004). Publishing research outputs is currently still one of the premier outlets to demonstrate academic success, both to the researchers and sponsoring institutions involved. Thus, it is non-debatable that modern academics are still pressurised to regularly publish their research outputs - otherwise their careers might suffer as a result. Although some academic debates strongly question this drive towards 'publish or perish', this paper does not venture into this topic, but focuses on the publishing of research outputs.

Academics today should be active in research, in one or another way, and research that is not disseminated would not be seen, read, used or cited by others. Such research can be deemed unproductive, or even useless, unless such research can be classified as secret or confidential for some reason. Worthwhile research contributions should be published in order to make it available to others to criticise, to use to extend the domain of knowledge even further, or to apply and implement in practice. Research outputs can be deemed as good or worthwhile if they are read, used and/or cited by others, thus making an impact. In general, three types of research outlets are currently available to disseminate such research outputs: journals, conference proceedings, and books. With all of this in mind, two questions arise: where should an academic publish her/his research outputs to have maximum impact? And what exactly is meant by research impact?

The objective of this positioning paper is an attempt to identify and discuss the relevant literature - and to establish some guidelines that academics, especially young academics starting their careers and their mentors can follow to publish research outputs with maximum impact, and as a result build effective research careers. The paper focuses on the computing discipline, although most of the contents are also applicable to all disciplines.

von Solms, R. and von Solms, B. (2016). Publish or perish - but where? [Viewpoint]. South African Computer Journal 28, 44-58. http://dx.doi.org/10.18489/sacj.v28i1.394

Copyright (C) the author(s); published under a Creative Commons NonCommercial 4.0 License (CC BY-NC 4.0).

$S A C J$ is a publication of the South African Institute of Computer Scientists and Information Technologists. ISSN 1015-7999 (print) ISSN 2313-7835 (online). 
The paper addresses the following aspects in addressing the objective: Firstly, the changing landscape that influences research outputs will be discussed; secondly, the position of the computing discipline will be assessed. Thirdly, the results of a survey amongst computing peers will be disseminated; fourthly, a discussion leading to some guidelines, will follow. Finally, some conclusions will be drawn.

\section{THE CHANGING LANDSCAPE AFFECTING QUALITY RESEARCH OUTPUTS}

A number of factors influence the landscape that determines the impact that research outputs would have on universities, as well as on individual universities. A factor like the ranking of universities is a fairly new concept, and this has put new emphasis on quality research outputs. Furthermore, there is the factor of funding associated with research outputs. Another factor that is influencing the landscape is the vast amount of data recorded on journals, articles published, and citations to other research papers. Each of these factors will be discussed briefly below.

Although most of the aspects below are discussed from a general point of view, they will be utilised from the computing discipline's context in the paper.

\subsection{Ranking and comparing universities}

Internationally, universities are ranked (Times Higher Education, 2016; QS Quacquarelli Symonds Limited, 2016) on a number of ranking lists, and competition amongst universities to be positioned favorably on these lists is fierce. Even an African (4 International Colleges and Universities, 2016) list exists, where universities in Africa are ranked. One of the core factors influencing the scoring towards these rankings is obviously the quality and quantity of research outputs. Universities that are serious about improving their rankings should ensure that quality research outputs are published. Thus, universities do have a definite interest in the quality and quantity of their research publications.

\subsection{Funding from research outputs}

In many countries, the extent of government funding and subsidy is influenced by the research outputs. In South Africa, the funding model of the Department of Higher Education and Training (DHET) that determines the funding universities receive is heavily influenced by the number of research output units they produce. Therefore, South African universities also benefit financially from the number of research outputs claimed. These research outputs are claimed and determined according to the DHET Research Outputs Policy 2015 (SA Department of Higher Education and Training, 2015).

It must be recognised that the DHET classifies journals into two classes: firstly, journals that do earn a subsidy (according to their policy and annual lists based on certain indices); and secondly, those journals that do not earn a subsidy (that do not appear in any of their index lists). Applications can be forwarded annually to the DHET for research outputs published in conference proceedings (conference papers) and published in books (normally book chapters). Generally, subsidy units for 
articles published in qualifying journals are 'claimed'; whereas subsidies for conference papers and chapters in books have to be 'applied' for.

It must be noted that the DHET does not differentiate between journals that appear on their qualifying lists. Thus, the DHET does not differentiate between high quality journals and low quality journals that appear on their qualifying lists. However, the DHET does differentiate between a research paper published in a qualifying journal (earning one subsidy unit) and a paper published in conference proceedings (earning half a subsidy unit). Thus, the DHET does differentiate between qualifying journals and conference proceedings that do meet the policy criteria.

From Subsections 2.1 and 2.2 above, it is clear that there is a definite vested benefit for the individual universities if high quality research publications are produced by their affiliated staff members.

\subsection{Ranking and comparing journals}

Based on the vast amount of data captured by bibliographic databases (e.g. Web of Science, Scopus or Google Scholar), it has become the norm to capture and statistically assess the impact of journals, conferences, papers and authors, etc. These datasets are used to compare and rank journals, conferences, papers and researchers. This sub-section will focus on the comparison and ranking of such journals.

Most of these comparisons and rankings are based on citations: how many other papers cite the work in any paper in that specific journal. Naturally, a journal aims to attract as many references or citations as possible from other papers published. Therefore, a journal whose papers are cited a lot can be deemed a quality or high impact journal.

The impact of a journal based on citations is generally recorded as the Impact Factor (IF) of the journal. Exactly how these IFs are determined will not be discussed in this paper, but obviously the higher the IF, the greater the impact of the journal. It must be mentioned that not all publishing houses calculate their IFs accurately, and some of them can be inaccurate. The Journal Citation Reports (JCR) (Thomson Reuters, 2016a) is known for the accurate and trustworthy calculation of their IFs, and it is used worldwide as the most authoritative guide to quality journals. Web of Science (Thomson Reuters, 2016b) uses these JCR (Fondazione Bruno Kessler, 2016) (based on citations) and Scopus (Elsevier, 2016b) uses the SCImago Journal Rank (SJR) (Elsevier, 2016a) to rank their journals in quartiles (Q1 to Q4) within subject areas. Q1 journals are deemed to have a higher impact than Q4 journals. The IF and the quartile (Q1 - Q4) can definitely be used to differentiate between high quality journals and not so high quality journals, having a larger influence on the specific subject domain. Although the DHET does not make use of any of these to differentiate between journals, the international ranking agencies that rank universities do make use of this information.

\subsection{Ranking and comparing conferences}

To compare or rank the quality of conferences is a lot more difficult, and more subjective. Unlike journals, there are no generally accepted criteria to compare the quality, influence or prestige of conferences. There exist a number of guidelines or principles however. 
One generally accepted and practised principle for a good conference is that the conference papers must be peer-reviewed (Perutková, n.d.). Peer-review is a system in which the quality and acceptability of a paper is determined by peer reviewers who vouch for the quality and suitability for the conference (Elsevier, n.d.).

A number of conference ranking sites (Zhou, 2016; Gu, n.d. Microsoft Corporation, 2013) exist, but none of them is very dominant, as in the case of journals. The criteria used to rank conferences include:

- Acceptance Ratio (AR) - the number of papers accepted in relation to the papers submitted

- Participation Ratio (PR) - the number of participants in relation to the papers accepted

- Citation Ratio (CR) - the ratio between the number of accepted papers and their citations

- Committee member quality

- Paper quality and impact

- Location

- History

These sites rank conferences as Tier 1 - 4 conferences (A* - flagship, A - excellent, B - good, C local or unranked conferences), according to Conference Impact Factors (CIFs), or some classification indicating the ranking of the conference in relation to other conferences in the same subject domain (Zhou, 2016; Gu, n.d. Microsoft Corporation, 2013). As mentioned, none of these ranking sites are dominant nor have they become the de facto conference-ranking standard.

The DHET does not utilise any conference ranking list or site; but the policy that dictates which conferences qualify for government subsidy is spelt out in the DHET Research Outputs Policy 2015 (SA Department of Higher Education and Training, 2015). Although the criteria are not absolutely and objectively spelt out, the following are generally implied:

- quality peer-review on the full paper (not only on the abstract)

- quality-review committee

- the conference must disseminate original scholarly knowledge

- there must be a favourable acceptance ratio

Another factor that needs to be mentioned is the question of who publishes the conference proceedings. For example, the proceedings of the annual SAICSIT (South African Institute of Computer Scientists and Information Technologists, 2016) conference are published by the ACM Digital Library (DL) (Association for Computing Machinery, n.d.), while the proceedings of the ISSA (Venter, Coetzee, Loock, \& Eloff, 2016) conference are published by the IEEE Xplore Digital Library (IEEE, n.d.). These 
are both reputable publishing houses that put specific quality control measures in place to ensure that quality proceedings result.

Thus, although there are no generally accepted and utilised ranking lists, there are mechanisms to rank conferences for quality and impact, although these are somewhat subjective and less rigorous than the ranking of journals. From a South African point of view, the DHET uses a set of criteria as spelt out in their policy (SA Department of Higher Education and Training, 2015), to assess which conferences it will subsidise and which it will not, but no further differentiation between the quality or impact of the conferences is made.

\subsection{Ranking and comparing researchers}

Researchers generally publish their research outputs in journals, conference proceedings or books. Obviously, a researcher wants his/her publications to be found, read and (hopefully) cited. The more citations the publications of a researcher attracts, the higher the impact and influence of a researcher becomes. To maximise this, most journals and conference proceedings are currently indexed in one or more digital libraries, such as Web of Science (Thomson Reuters), Scopus (Elsevier) or Google Scholar (Google). Papers published in a journal, conference proceedings or book that is indexed in any of these digital libraries can be searched more effectively by using related search engines. This means that papers in journals, conference proceedings and books that are indexed are more 'visible' and easier to locate than non-indexed papers. This is an important principle that any researcher should take note of. It is important that their published papers should be visible to other researchers - to read and (hopefully) cite. If not, the published research outputs might not be found, read or cited, meaning that your published research papers might have minimal or limited impact. Since most, if not all, researchers do want to make an impact and grow their research influence, researchers should attempt to maximise the number of citations that their research publications receive (University of Western Australia, 2016; Kelly \& Jennions, 2006).

The citations linked to the papers published by a particular researcher can again be used as an indication of the impact or quality of a researcher (Kelly \& Jennions, 2006). The h-index (Alonso, Cabrerizo, Herrera-Viedma, \& Herrera, 2009), based on citations, is a popular mechanism to calculate the impact of a particular researcher, taking both the quantity and quality of their papers published into account. The h-indices of different researchers can be used as mechanisms to compare and rank the impact of researchers. However, it is important that researchers should not be compared across different disciplines but ideally only within a particular discipline (Alonso et al., 2009).

Using the h-index in situations mentioned above is often debatable; and this issue should be approached very carefully. In the discipline of chemistry, the use of this index was stopped a few years ago (Broadwith, 2012).

Furthermore, one researcher could have more than one h-index, as (for example) the Web of Science h-index only uses papers published in the Web of Science indexed publications, and this practice is similar to that employed by Scopus and Google Scholar. The Web of Science only indexes journal publications (Thomson Reuters, 2016a), whereas Google Scholar also indexes conference proceedings and books published in indices like IEEE Xplore, the ACM Digital Library, etc. Thus, 
a researcher's Google Scholar h-index would always be higher than that of Web of Science, since Google Scholar includes those from the Web of Science plus more indices (Harzing \& van der Wal, 2016).

Therefore, the h-index does provide a commonly used mechanism whereby the impact of the publications of a researcher can be calculated and compared with others, ideally within similar disciplines.

\subsection{Other important information regarding research outputs}

A number of other aspects should be taken into account by universities and researchers, when it comes to the publication of research outputs. A brief discussion follows below.

\subsubsection{Predatory journals}

Predatory journals are published by predatory open-access publishers that exploit the open-access model in an unprofessional manner for their own financial benefit and profit (Elliott, 2012). These journals in essence publish any academic garbage in exchange for the author's publication fee. The disciplines of science, technology and medicine seem to be the primary targets of these publishers, since these disciplines normally attract grant funding. Jeffrey Beall, an academic librarian, annually publishes Beall's List, detailing all of these predatory, open-access publishers (Beall, n.d.). According to Beall, these publishers do nothing illegal but they just act in an unethical way. He further mentions that there are 'academics' who submit a really weak level of research work to these publishers just to increase the quantity of their published papers. Beall also advises that mentors should steer junior academics and students away from these publishers towards more reputable journals (Elliott, 2012).

\subsubsection{Spam or junk academic conferences}

Spam or junk conferences, also called spamferences, tend to be low-quality conferences that advertise through spam or junk mail (Kovacs, 2008). The nature and essence of these conferences is not as well-documented and reported as predatory journals at this time, although academics are certainly spammed by advertisements for these conferences. In general, the peer-review system of these conferences is very limited and poorly administered. Furthermore, the acceptance rate of papers is generally very high. Additionally, conference proceedings are not normally published in any of the major digital libraries: therefore, the papers presented at these conferences are not very likely to attract any citations. Tom Kovacs states that if one publishes in low-quality conferences or junk conferences, then "you will find it hurts your reputation more than it helps" (Kovacs, 2008).

\subsection{Deductions}

Taking all of the above issues into account, it is clear that:

- Research outputs benefit both the researchers (academics) and their universities (sponsoring institutions) 
- In South Africa, the quantity of (qualifying) publications is a determinant of the DHET subsidy attracted by the affiliated university

- The DHET does not differentiate between the quality of (qualifying) publications

- The quality of publications plays an important role in the ranking of universities, but not in the DHET funding it attracts

- The DHET does differentiate between the research outputs published in journals and those published in conference proceedings

- Researchers, within a discipline, can be ranked or compared by means of the h-index, which is dependent on the citations attracted

- There are low-quality journals and conferences that publish any 'research outputs', as long as the author(s) are willing to pay the associated publication or conference fees

From the above, it is clear that there are many factors to consider and take into account when and where research outputs are published. In their drive for excellence, individual universities might dictate to their affiliated academic staff members where they should publish their research outputs. This might be based on whether the university wants to increase its international ranking, and/or whether the university wants to maximise its DHET research subsidy. On the other hand, these factors also influence the research career and the impact of individual researchers.

\section{THE COMPUTING DISCIPLINE AND RESEARCH OUTPUTS}

At this stage, the question can be asked whether the computing discipline differs from other disciplines as far as the nature and types of research outputs are concerned. Books will not be addressed, but only journal and conference papers and the role they play as research outputs. Two parties that play an influential role in South Africa, as far as research outputs are concerned, are the National Research Foundation (NRF) and the DHET.

The NRF is important to researchers as it manages and administers a rating system of Considerable International Recognition (CIR), and normally based on this, is a source of (potential) funding to researchers. The NRF states that "the rating system encourages researchers to publish high quality outputs in high impact journals/outlets" (National Research Foundation, n.d.).

It further mentions that the "rating of individuals is based primarily on the quality of their research outputs ..." " and also that "several South African universities use the outcomes of the NRF evaluation and rating process to ... provide incentives for their staff members to acquire and maintain a rating" (National Research Foundation, n.d.).

In 'Considerable International Recognition (CIR): A Guide for NRF Specialist Committees and Assessment Panels' (National Research Foundation, 2014), the NRF mentions a number of indicators of CIR, including the number of citations gathered by (and the h-index of) a researcher, the impact factors of journals in which they are published, etc. The guide states further that "in assessing whether 
a researcher enjoys CIR, cognizance needs to be taken of the different traditions". For example, in "fast evolving disciplines, such as Information and Communication Technology, peer-reviewed conference proceedings are often the preferred publication avenues for the rapid dissemination of research findings" (National Research Foundation, 2014). Thus, the NRF recognises that peerreviewed conference proceedings are indeed an acceptable (and "often the preferred") research outlet for the Information and Communication Technology discipline.

As far as the DHET is concerned, it was mentioned earlier that they do differentiate between publications in journals and conference proceedings, in that a qualifying journal publication earns one research output unit, against a publication in a qualifying conference proceedings (half a research output unit). But, the question to be asked is: what is the ratio of publications in journals against publications in conference proceedings, as funded by the DHET, in the discipline of Computer and Information Sciences?

The 'Report on the Evaluation of the 2014 Universities' Research Outputs (SA Department of Higher Education and Training, 2016) was made available early in 2016. According to this report, the following are reported for the Computer and Information Sciences category:

- The number of research output units earned in this category ('CESM 06') in 2014 by journal papers is 166.61 . Thus, at least 166 journal papers qualified as DHET journal-research outputs.

- The number of research output units earned in this category ('CESM 06') in 2014 with conference publications was 219 . Thus, at least 438 conference papers were accepted for subsidy by the DHET.

From the above, it is clear that in South Africa, researchers in the discipline of Computing (Computer and Information Sciences) publish a lot more in conference proceedings than they do in journals, almost at a rate of three to one.

\section{COMPUTING PEERS ON RESEARCH PUBLICATIONS}

Based on the factors discussed above, a survey was conducted amongst twenty established or senior researchers in the computing discipline. These researchers all stem from different universities, and are all known for quality research outputs. Fifteen of these universities are prominent international universities, while the other five are South African universities. The questionnaire was circulated through Google Forms and included twenty-five questions, which comprised:

1. Likert scale questions

2. open-ended questions

3. yes/no questions

The following is a brief summary of the more significant data received. 


\subsection{Journals}

- 95\% (19 from 20 responses) deemed peer-review as an Important (6 responses) or Very Important (13 responses) criterion in determining quality research outputs by their universities.

- 85\% (17 from 20) indicated that their universities differentiate between journal and conference proceeding research publications. In all cases, journal papers are favoured as research outputs over conference papers. The three universities that do not differentiate are all international (two from the UK and one from the US).

- All the respondents indicated that their universities strongly advocate the publishing of their research outputs in 'high impact' or 'quality' journals.

- Most respondents (70\%) indicated that their universities use digital library indices, like Web of Science or Scopus, to determine which journals can be classified as 'high impact' or 'quality' journals.

- $70 \%$ of the respondents also indicated that the Impact Factor (IF) of the journal is also used to determine quality journals.

- Only 35\% reported that their universities make use of the Quartile Rankings (Q1-Q4) within subject categories to determine quality journals.

- Few universities (only 25\%) use the h-index of the journal to determine quality.

\subsection{Conferences}

- Most universities (75\%) differentiate between the quality of conferences.

- The following factors are used by universities to differentiate between conferences:

- Conference ranking lists

- Reputation of conference

- The quality of the Program or Review Committee

- The publishers of the conference proceedings, e.g. ACM, IEEE, Springer-Verlag, etc.

- Three (international) universities make use of conference ranking lists to determine the quality of a conference. The lists referred to are:

- The Australian (CORE) list (Computing Research and Education (CORE), n.d.) and

- The Finnish list (Julkaisufoorumi (Publication Forum), n.d.).

- It does not seem as if the Acceptance Ratio (AR) (Zhou, 2016; Gu, n.d. Microsoft Corporation, 2013) plays a dominant role in determining quality - most probably because the AR is only known after the conference proceedings have been published. 


\subsection{Researchers}

- Only seven (35\%) of the respondents indicated that their universities utilise the h-index of researchers for promotion or career advancement. Three of these universities are from South Africa.

- No clear preference to the h-index for individual researchers from Web of Science, Scopus or Google Scholar is apparent.

- $45 \%$ of the respondents indicated that the number of citations by a researcher should play any role in promotion or career advancement. No clear preference for a particular digital library favoured for citations was mentioned.

- $80 \%$ (16 from 20) of the respondents reckoned that publishing in 'predatory' journals might harm the reputation of a researcher.

\subsection{Ranking of universities}

- Only three respondents indicated that their universities advocate publishing in high quality journals to boost their university's position on the international ranking lists.

- Ten respondents (50\%) indicated that their respective universities have made some policy or strategy changes lately, to cater for research outputs to assist in boosting their university's rankings.

\subsection{General comments}

In response to the question: "[What is] your advice to a young emerging academic to advance his/her career as a researcher?" the following was advised. (This question was only asked of the South African respondents, as the DHET was referred to in most questions).

$100 \%$ of South African respondents supported these options:

- Maintain a healthy balance between journal and conference publications, e.g. 50/50.

- Ensure your h-index grows steadily over the years.

- Focus your research on one or two related fields of study.

- Get involved with a team somewhere working in your field of research.

$80 \%$ of South African respondents supported these options:

- Choose conferences carefully - only select a reputable conference with a good chance of earning a DHET subsidy.

- Publish where your work would be visible to receive citations. 
In the following section, these results are assessed and interpreted; and some guidelines and recommendations are made to young and/or emerging researchers to further their research impact and careers.

\section{MANAGING YOUR OWN RESEARCH CAREER}

Taking the sentiments from the literature analysed and discussed above, the results from the survey amongst peers, as well as the experience of the authors, the following are presented as guidelines to young, emerging researchers on how to manage their own careers.

\subsection{Position yourself to maximise the impact of your research outputs}

- Know and align with the research strategy and policies of your university. As a result of their drive for excellence, some universities are definitely changing their strategies and policies - in an attempt to improve their position on international ranking lists. Do ensure that you are aware of the research strategy and the policies of your university; and practice accordingly.

- Focus as early as possible in your research career on one or two related fields of study. Do not attempt to be a 'Jack of all trades, but master of none'.

- Do get involved with a team of researchers in your field(s) of research. If there is not such a group at your university, find a group at another university. The International Federation for Information Processing (IFIP) (International Federation for Information Processing, n.d.) offers many Working Groups where one can get involved easily, and thereby create international networks in your field.

\subsection{Publish, publish, publish!}

- Peer-reviewed publications form the backbone of a researcher's impact and influence. Do ensure that you publish in reputable journals and conference proceedings. Do not think that quantity is everything. Research outlets are screened and publications in dubious journals or spam conferences might hurt your reputation more than they help.

- Publish where your research outputs will be visible and stand the maximum chance of attracting citations. This would also steadily increase your h-index. A healthy h-index and numerous citations increasingly play a role in promotion, attraction of research funding, and of course, the impact of the researcher. Already EU funding agencies take the h-index and citations into account (Perutková, n.d.).

- Keep a healthy balance between publishing in journals and conference proceedings. The NRF recognises conference publications as effective research outlets in the discipline of Computing, whereas the DHET does treat journal publications as superior. Although the authors of this 
paper have published about $40 \%$ more conference papers than journal papers, their journal papers have attracted about eight times more citations than their conference papers.

\subsection{Conduct your research in an ethical manner}

- Ensure that you do not republish research outputs. Publishing a very similar content under different titles might harm your research profile.

- Only add names to the publication as co-authors if they made a significant contribution to the paper; drafted or substantially reviewed the paper, or approved the final version of the paper (University of Oxford Research Support, 2016).

Taking these guidelines, as well as the previously conveyed information into account, researchers are urged to take control of their own research careers and to publish where each of them would benefit the most as researchers in the short term, as well as in the long term.

\section{CONCLUSION}

It cannot be disputed that researchers should publish their research results, or perish as researchers. The University of Oxford, which is currently second on the Times Higher Education World University Rankings 2015-2016 (Times Higher Education, 2016), states that their "University encourages all researchers to promote their work through publishing" (University of Oxford Research Support, 2016). It further states that the "University encourages researchers to publish their work in peerreviewed publications", and to "give priority to publishing in those publications, which employ rigorous standards of peer review" (Ibid.). Thus, publishing is important, but in reputable outlets. Publishing in low quality 'predator' journals and conference proceedings, where no or very low quality peer review takes place, would contribute to the perishing of the researcher than to the development or growth of the researcher.

It is important that young emerging researchers have a long-term strategic plan on how to grow a successful research profile. Also, supervisors and mentors should assist these young researchers in doing so. For this reason, it is important that researchers and mentors understand the research environment, what the contributing issues are, and what the risks or dangers are in building a research career.

Building a research profile is a journey, not a sprint. Do plan your career meticulously with the information in this paper as your guideline.

\section{ABOUT THE AUTHORS}

The authors have jointly in excess of 70 years' research and supervision experience. They have successfully supervised more than 160 Masters and $35 \mathrm{PhD}$ students; they have authored or coauthored more than 120 journal and 270 conference peer-reviewed publications, which have attracted 
more than 6500 Google Scholar citations. They have been rated by the NRF for 5 (3 as B-rated) and 7 (4 as B-rated) cycles respectively.

\section{References}

4 International Colleges and Universities. (2016). Top 200 universities in Africa. Retrieved from http://www.4icu.org/top-universities-africa/

Alonso, S., Cabrerizo, F. J., Herrera-Viedma, E., \& Herrera, F. (2009). h-Index: A review focused in its variants, computation and standardization for different scientific fields. Journal of Informetrics, 3(4), 273-289. http://dx.doi.org/10.1016/j.joi.2009.04.001

Association for Computing Machinery. (n.d.). ACM digital library. Last accessed 13 Jul 2016. Retrieved from http://dl.acm.org/

Beall, J. (n.d.). Scholarly Open Access: List of publishers. Last accessed: 13 Jul 2016. Retrieved from https://scholarlyoa.com/publishers/

Broadwith, P. (2012, November). End of the road for h-index rankings. Last accessed: 13 Jul 2016. Retrieved from http://www.rsc.org/chemistryworld/2012/11/h-index-rankings-stopchemist-chemistry

Computing Research and Education (CORE). (n.d.). CORE rankings portal. Last accessed: 13 Jul 2016. Retrieved from http://www.core.edu.au/conference-portal

Elliott, C. (2012). On predatory publishers: A Q\&A with Jeffrey Beall. Chronicle of Higher Education. Elsevier. (2016a). Journal metrics: Research analysis redefined. Last accessed 13 Jul 2016. Retrieved from https://www.journalmetrics.com/sjr.php

Elsevier. (2016b). Scopus: The largest datadata of peer-reviewed literature. Last accessed: 13 Jul 2016. Retrieved from https://www.elsevier.com/solutions/scopus

Elsevier. (n.d.). What is peer review? Last accessed: 13 Jul 2016. Retrieved from https://www. elsevier.com/reviewers/what-is-peer-review

Fanelli, D. (2010). Do pressures to publish increase scientists' bias? an empirical support from US States Data. PloS one, 5(4), e10271. http://dx.doi.org/10.1371/journal.pone.0010271

Fondazione Bruno Kessler. (2016). Journal citation ranking and quartile scores. Last accessed: 13 Jul 2016. Retrieved from https://researchassessment.fbk.eu/quartile\%5Fscore

Gad-el-Hak, M. (2004). Publish or perish-an ailing enterprise? Physics today, 57(3), 61-64. http: //dx.doi.org/10.1063/1.1712503

Garfield, E. (1996). What is the primordial reference for the phrase 'publish or perish'. The Scientist, 10(12), 11.

Gu, G. (n.d.). Computer security conference ranking and statistic. Last accessed 13 Jul 2016. Retrieved from http://faculty.cs.tamu.edu/guofei/sec\%5Fconf\%5Fstat.htm

Harzing, A.-W. \& van der Wal, R. (2016, February). Comparing the Google Scholar h-index with the ISI Journal Impact Factor. Last accessed: 13 Jul 2016. Retrieved from http://www.harzing.com/ publications/white-papers/google-scholar-h-index-versus-isi-journal-impact-factor

IEEE. (n.d.). The IEEE Xplore digital library. Last accessed 13 Jul 2016. Retrieved from https: //www.ieee.org/publications\%5Fstandards/publications/xplore/index.html 
International Federation for Information Processing. (n.d.). IFIP home page. Last accessed: 13 Jul 2016. Retrieved from http://www.ifip.org/

Julkaisufoorumi (Publication Forum). (n.d.). Publication channel search. Last accessed: 13 Jul 2016. Retrieved from https://www.tsv.fi/julkaisufoorumi/haku.php?lang=en

Kelly, C. D. \& Jennions, M. D. (2006). The h index and career assessment by numbers. Trends in Ecology \& Evolution, 21(4), 167-170. http://dx.doi.org/10.1016/j.tree.2006.01.005

Kovacs, T. (2008, October). Junk conferences / spam conferences / spamferences / academic scams. Last accessed 13 Jun 2016. Retrieved from http://www.cs.bris.ac.uk/Teaching/learning/ junk.conferences.html

Microsoft Corporation. (2013). Top conferences in security and privacy. Last accessed 13 Jul 2016. Retrieved from http://academic . research. microsoft.com/RankList ? entitytype $=3$ \& topdomainid $=2 \&$ subdomainid $=2 \&$ last $=10$

National Research Foundation. (2014, August). Considerable international recognition (CIR): A guide for NRF specialised committees and assessment panels. Last accessed: 13 Jul 2016. Retrieved from http://www.nrf.ac.za/sites/default/files/documents/Considerable\% 20International\%20Recognition\%5FAug\%202014.pdf

National Research Foundation. (n.d.). NRF rating. Last accessed: 13 Jun 2016. Retrieved from http://www.nrf.ac.za/rating

Neill, U. S. (2008). Publish or perish, but at what cost? The Journal of clinical investigation, 118(7), 2368-2368. http://dx.doi.org/10.1172/JCI36371

Perutková, P. (n.d.). Horizon 2020: European Research Council Grants. Last accessed: 13 Jul 2016. Retrieved from http://www.h2020.cz/cs/storage/2b7fa65213c3d8b47a28fc710c0950d1420d4bbf

QS Quacquarelli Symonds Limited. (2016). University rankings. Retrieved from http://www . topuniversities.com/university-rankings

SA Department of Higher Education and Training. (2015, March). Government notice 188: Research outputs policy. Retrieved from http://www.gpwonline.co.za/Gazettes/Gazettes/38552\% 5F11-3\%5FHighEduTraining.pdf

SA Department of Higher Education and Training. (2016, January). Report on the evaluation of the 2014 universities' research outputs. Retrieved from http://www.dhet.gov.za/Policy\% 20and\%20Development\%20Support/Report\%20on\%20the\%20outcomes\%20of\% 20the\%202014\%20universities\%20research\%20outputs.pdf

South African Institute of Computer Scientists and Information Technologists. (2016). SAICSIT 2016. Last accessed: $13 \mathrm{Jul}$ 2016. Retrieved from http://saicsit2016.org

Thomson Reuters. (2016a). 2015 journal citation reports. Last accessed 13 Jul 2016. Retrieved from http://wokinfo.com/products\%5Ftools/analytical/jcr/

Thomson Reuters. (2016b). IP \& Science - Web of Science. Last accessed: 13 Jul 2016. Retrieved from http://ipscience.thomsonreuters.com/product/web-of-science/

Times Higher Education. (2016). World university rankings. Retrieved from https://www.timeshighereducatio com/world-university-rankings 
University of Oxford Research Support. (2016, June). Publication and authorship. Last accessed: 13 Jul 2016. Retrieved from https://www.admin.ox.ac.uk/researchsupport/integrity/ publication/

University of Western Australia. (2016). Research impact and profiles: Citation impact. Last accessed: 13 Jul 2016. Retrieved from http://guides.is.uwa.edu.au/c.php?g=325233\&p=2177977 Venter, Coetzee, Loock, \& Eloff. (2016). ISSA 2016. Last accessed: 13 Jul 2016. Retrieved from http://infosecsa.co.za

Zhou, J. (2016, June). Top crypto and security conferences ranking (2015). Last accessed: 13 Jul 2016. Retrieved from http://icsd.i2r.a-star.edu.sg/staff/jianying/conference-ranking.html 